www.jmscr.igmpublication.org

Impact Factor (SJIF): 6.379

Index Copernicus Value: 71.58

ISSN (e)-2347-176x ISSN (p) 2455-0450

crossrefDOI: https://dx.doi.org/10.18535/jmscr/v6i6.176

Journal Of Medical Science And Clinical Research

\title{
Eventration of Diaphragm - An Incidental Rare Entity
}

\section{Authors \\ Kulbir Singh, Parminder Pal Singh, Bharat Bhushan, Prasanth A P, Ritu Puneet Kaur, Vicky Bakshi}

\begin{abstract}
The eventration of diaphragm is a rare entity characterized by uniform elevation of part or parts of both hemi-diaphragms associated with ascent of abdominal organs like intestine showing haustrations under the diaphragm. We report a case of 37 year old lady, mother of two children, who presented with pain in lower chest and epigastrium, cough with mild expectoration and with other GIT symptoms. Fluroscopic examination showed absence of paradoxical movements of diaphragm on left side and CECT revealed smooth elevation of diaphragm and upward shift of the abdominal viscera under the diaphragm. Radiological, fluroscopic and CECT findings helped us to diagnose the patient as a case of eventration of left diaphragm.
\end{abstract}

Keywords: Diaphragmatic eventration, Sniff Test, Fluroscopy, C.E.C.T.

\section{Introduction}

Eventration of diaphragm is a rare entity and an incidental finding on radiological examination of the patient, revealing an abnormal elevation of diaphragm. The incidence of eventration is $1: 10000^{1}$. This elevation is due to very thin musculature or its replacement by fibrous tissue congenitally. The symptoms, depending upon severity, are of upper G.I.T or respiratory system. It can be due to many congenital causes or due to aiding procedures during birth or any surgical intervention. The symptoms may be worsened on lying supine, as increased negative intrathoracic pressure accentuates the herniation of abdominal structures. It may be possible to distinguish between eventration of diaphragm and diaphragmatic paralysis with the help of radiological imaging.

\section{Case Report}

This case, 37 years old lady, presented to us with pain over left lower chest and epigastrium, cough with mild expectoration, allergic symptoms like on and off nasal discharge and post nasal drip. The pain increased after taking meals and relieved with medications. On examination, nasopharyngeal congestion was seen. She was slightly anemic. She was normotensive and non-diabetic. The tactile vocal fremitus was decreased in infra axillary, infra mammary and infra-scapular region. The patient is having impaired percussion note in mammary, infra-mammary, infra-axillary and infra scapular region on left side of chest. The breath sounds were decreased in the same areas as compared to the right side.

The laboratory findings were within normal range .The chest X-ray showed uniform raised contour of the left hemi-diaphragm with haustrations of 
gut and increased bronchovascular markings in the lower zone and hazy shadow in the right lower zone. $\mathrm{X}$ ray examination was followed by fluroscopic examination of the chest which showed uniform normal movements of diaphragm. CECT revealed smooth elevation of left hemidiaphragm with mild passive atelectasis of over lying lung and with upward shifting of abdominal viscera.

Sniff Test: Findings were within normal limits during fluroscopy. Both hemidiaphragms showed movements in the same direction. The paradoxical movements were absent on sniffing in upright position. No mediastinal lesion, lytic or sclerotic lesion was seen. No parenchymal or pleural thickening or consolidation was seen during the procedure.

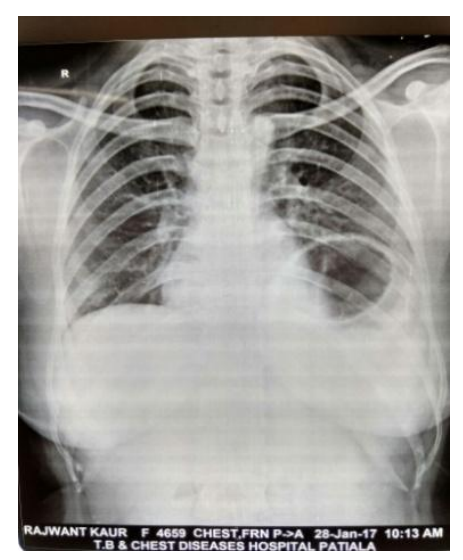

Fig. 1

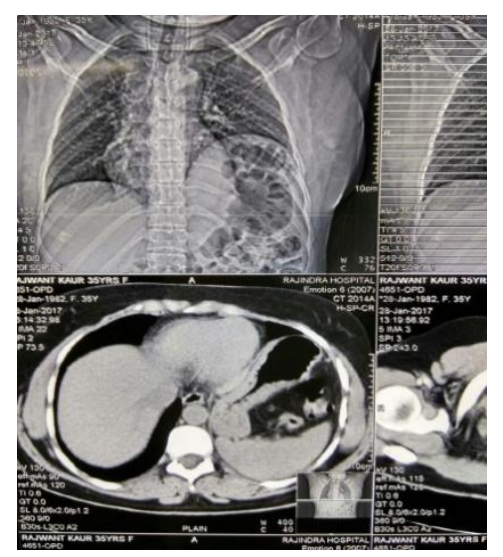

Fig. 2

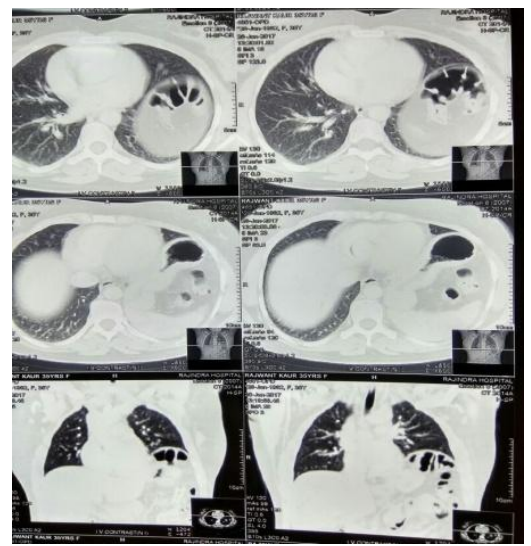

Fig. 3

\section{Discussion}

Louis Pettit recognized eventration in $1774^{2}$. Cruveveilier first used the term eventeraion ${ }^{3}$. The eventration is a congenital anomaly resulting from the failure of muscular development of part or all of one or both hemidiaphragms ${ }^{4}$. The partial eventration occurs on the right side but complete eventration of diaphragm occurs on left side which is a rare entity ${ }^{5}$. The eventration in the adults is symptomless and present incidently. The case under study presented with pain in epigastrium and left lower chest, which was mild to moderate in severity and radiating to left shoulder which relieves with medications. The diaphragmatic movements were decreased on fluoroscopy. The sniff test is the diagnostic test to rule out phrenic nerve palsy. Sniffing during fluoroscopy may reveal absence of paradoxical movements in case of eventration. So the diagnosis is apparent on screening of chest ${ }^{7}$. The congenital elevation of diaphragm is called as true except one caused by all other conditions (Reich, 1926; Chin and Lynn, 1956) $)^{8}$. The diagnosis is sometimes difficult to make when partial eventration is present with overlying lung atlectasis, due to its compression as a result of pneumonia or a tumour or diaphragm being raised due to liver enlargement ${ }^{9}$. Prior to the surgery diaphragmatic hernia must be differentiated from the partial eventration. The utrasonography can help in establishing the plication. Patients with mild symptoms are treated conservatively. ${ }^{11}$ 
Bibliography

1. Kulkarni ML, Sneharoopa B,Vani HN, Eventeration of the diaphragm and associations. Indian J Pediatr 2007; 74:202-5

2. Petit-JL. Traite Des maladies Chirurgicaleset. des operations qui leirconviennt. Over age posthume de J.L Petit Vol 2, (revised) Paris meguinon, 1760 page 233.

3. SkandalakisJe.gray $\mathrm{S}$ W,Ricketts R: The diaphragm. In skandalakisJ.e gray SW (eds) Embryology for surgeons . Baltimore diagnosis of partial eventration as diaphragm is seen as thin continuous layer above the elevated abdominal viscera $^{10}$.The treatment for the troublesome symptoms is surgical: Williams and Wilkins 1994, PP.491-539.

4. Thomas, T.V. Congenital eventration of diapharagm. Ann. Thoracic Surg. 1970; 10: $180-92$

5. Seaton, A., Seaton, D., Leitch, A. G., Seatan, A. Abonormalties and diseases of Diaphragm. In : Editors Crofton and dougla's Respiratory diseases:- $5^{\text {th }} \mathrm{Ed}$. Blackwell science, oxford, 2000; 1234-49

6. Chin, E. F., Lynn, R. B. Surgery of Eventration of Diaphragm. J. Indians Med. 1986; 84: 187

7. Salton, D., Editor.Text Book of Radiology and imaging; $7^{\text {th }}$ Edition ; vol. 1 London: church livingstone; 2003 : pp 51-2

8. Paulchristensen Eventration of Diaphragm Thorax.BMJ. 3,1959

9. Gierada, D. S., Scone, R. M., Fleishman, M. J. Imaging evaluation of Diaphragm. Chest Surgclinc North America 1998; 8: 237-80

10. Larson, R. K., Evans, B. H. Eventration of the diaphragm. American review Respiratory dis. 1963; 87: 75

11. Kansal, A. P. Et.al Right Sided Diaphragmatic Eventeration: A rare Entity. Lung India 2009; 26 issue 2 